News analysis

\section{Turkey: upping up the anti}

Turkey, strategically placed between Europe and Asia, is understandably seen by tobacco companies as a key market. The struggle to obtain comprehensive tobacco control legislation has been long and strewn with setbacks, as frequently reported in these pages (see Tobacco Control 2001;10:208). As with any legislation passed without a strong, cabinet-wide commitment to effective action on tobacco, there are limited resources, and more than a hint of limited enthusiasm, for monitoring and enforcing the law. Blatant tobacco industry lobbying and promotional efforts aimed at establishing Formula l (F1) motor racing, in a country with no popular interest in motor sport, have now gone underground. However, there are frequent signs that tobacco interests are still actively pushing for the establishment of motor racing as a handy means of mass cigarette promotion in the region, and it seems inevitable that a tobacco friendly Fl or equivalent race will come to Turkey within a few years.

Meanwhile, the government has continued to dither over the sale of Tekel, the tobacco monopoly. Government and parliamentary sources have indicated desperate lobbying by British American Tobacco (BAT) and others, some of it apparently involving conditions for a takeover that would effectively break the tobacco law. No wonder, then, that doctors, always at the forefront of the campaign in Turkey, have been trying to expand their activities, taking tobacco control to the regions and stepping up pressure to promote tobacco control to a fully recognised national health priority.

Earlier this year, more than two dozen doctors took part in a week long training course in Ankara. Many were clinicians in charge of smoking cessation clinics in their hospitals and health centres. At least, they were when they arrived; but many left the

All articles written by David Simpson unless otherwise attributed. Ideas and items for News Analysis should be sent to David Simpson at the address given on the inside front cover

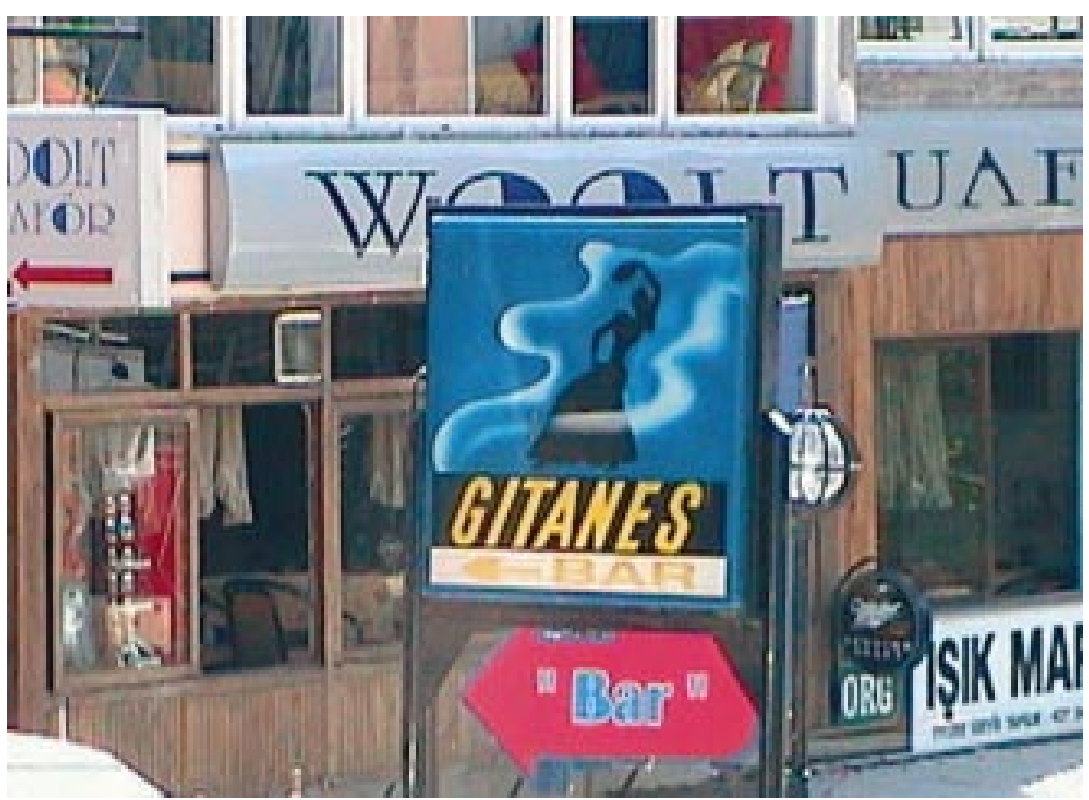

In Turkey, overt tobacco promotion is still very evident, as illustrated by this Gitanes ad above a street sign to a bar.

course already planning to take on other tobacco issues in their regions. Evidence of their new activities soon began to accumulate. In Ankara itself, meetings were arranged with parliamentarians and national medical organisations, to press the government over the Tekel sale. In Mersin, on the Mediterranean coast, a one hour live television programme was arranged; a training workshop was held for local doctors; and a stand was taken in the centre of the city with a "death clock", to begin the long task of educating the public. In Trabzon, on the Black sea coast, doctors went public with a major campaign, including a smoking cessation booth at a local health fair.

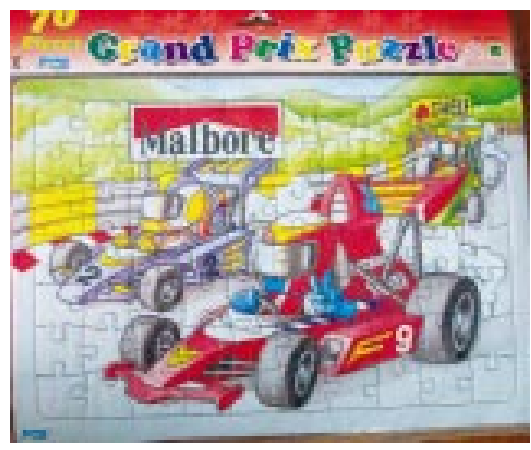

Some tobacco promotion in Turkey is complex, even unintended, as in this child's jigsaw featuring the Marlboro logo, but with a small change to the name.
Meanwhile, the newly inspired medical activists have been monitoring tobacco promotion, all of which is now supposed to be illegal. Even before the end of the Ankara course, students spotted a nearby Gitanes ad on a street sign to a bar, and arrangements were made to pursue this with the authorities. In Bursa, in the west of the country, several child friendly items were located which were more difficult to deal with, as they had not necessarily come from tobacco companies themselves. Instead, they were classic examples of the goodwill of individual cigarette brands being so great, and the social acceptability of smoking being so widespread, that manufacturers of other goods imitate cigarette brand characteristics to

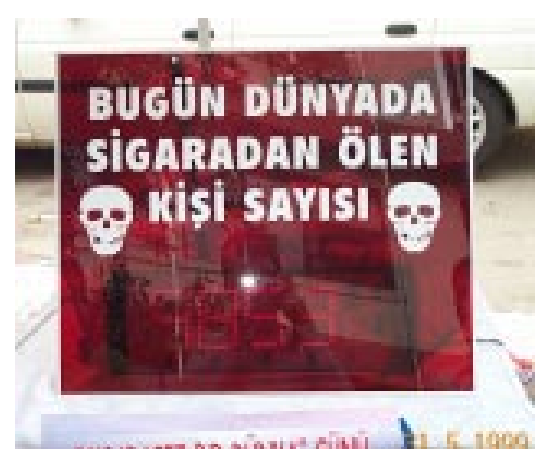

The "death clock", used to educate the Turkish public about the dangers of smoking. 
glamorise their products. Thus, an inexpensive jigsaw was just one letter away from advertising Marlboro. And in the playground of a large shopping mall that attracts tens of thousands of customers every day, "dodgem" cars were painted in imitations of Winfield and Benson \& Hedges Fl colours. The carefully painted village scene on the back wall of the dodgems circuit included something so far entirely alien to any Turkish village or city, a motor racing circuit complete with a West Fl car.

Turkish health advocates are deeply concerned about the likelihood of continuing attacks on the Tobacco Act. For all Turkey's progress in recent years, leading to a possible application for European Union membership, some aspects of its governmental and business life, including corruption, still render it vulnerable to abuse by unscrupulous companies. The international tobacco control movement played a major role in helping Turkish colleagues to get their law. It may soon be called upon again to help them to preserve it.

\section{Canada: courageous canary}

20 March 2002-a date Heather Crowe would like to forget, but never will. A 57 year old grandmother, Heather had consulted her physician about mysterious lumps on the right side of her neck, possibly an ear infection, easily treated with antibiotics. At the follow up appointment for test results, on the above date, the news of Heather's condition ambushed and assaulted her: locally advanced adenocarcinoma of the left upper lobe of her lung, a condition her enlarged lymph nodes, now cancerous, could no longer hide. Another word attached itself to her prognosis: inoperable. Heather's stage 3B lung cancer offers a $15 \%$ chance of being alive five years from the date of diagnosis. Her doctors advised that without treatment she had 10 months to live. With radiation and chemotherapy she could buy some time. Three subsequent biopsies confirmed doctors' suspicions: secondhand smoke was the causative factor of her lung tumour.

Heather never smoked, nor lived with anyone who smoked, but worked for 40 years as a waitress in restaurants where smoking had been permitted. "The air in that restaurant was blue with cigarette smoke," she recalled. "We didn't like it, but we had no idea how dangerous it was. Anyone who doesn't think secondhand smoke kills can just ask me. I want to be the last person to die from secondhand smoke at work. I am the canary in the coal mine for the hospitality industry."

Brought up to do the right thing and not to be afraid of telling the truth, Heather's sapphire blue eyes cloud with sorrow and pain when she talks of the suffering lung cancer causes, and briefly flash with anger when she remembers the tobacco lobbyist who told her he had never seen a death certificate of anyone who had died from secondhand smoke. She made a public promise that he will, in due course, receive a hand delivered copy of hers.

The Ontario Workplace Safety and Insurance Board accepted her claim, the first of its kind acknowledging tobacco smoke caused injury in the workplace. She received C\$40000 compensation and lives on C\$220 a week. During this intensely personal time Heather Crowe could maximise her remaining days with her beloved daughter and granddaughter. Instead, she chooses to represent the Physicians for a Smoke-Free Canada as an unpaid volunteer when she implores legislators from coast to coast to protect all workers (not just government officials in high rise offices) from the avoidable workplace hazard known as tobacco smoke pollution.

Heather left school at around 15 and says she represents countless hospitality workers with minimal training, families to feed, and limited career choices. When diagnosed, Heather worked 60 hour weeks and earned C\$12 000 a year as a waitress. Since the Ottawa smoking ban in August 2002, her former employer's business has increased by $40 \%$. She ruefully observes the ban arrived too late to help her.

Following publicity about her case, a stranger telephoned Heather, saying he wanted to interview and film her for a documentary. When she met him, she got the impression he feared she would change her mind. After an in-depth interview, he advised Heather her story lacked sufficient interest for his alleged proposed documentary, and the apparently real reason for his visit began to surface. He asked how she would respond if someone offered her a lot of money for exclusive rights to her story? He mentioned treatment at the Mayo Clinic, new, expensive drugs to treat lung cancer, and taking care of her every need and those of her family when her "time came". True to character, she ordered him out of her house and advised him that further contact would be filtered through her lawyer. She heard no more about the documentary, nor about the offer of money and treatment. Who would benefit from Heather not telling her story?

Heather meets legislators and occupational health and safety officials as time permits between radiation, chemotherapy, and the increasing need for rest as her condition deteriorates. Tobacco apologists have labelled her the "anti-smoking poster girl". Had she been given a choice, Heather would have preferred a life of frugal obscurity planning her retirement instead of what has been imposed on her: finalising her will, and planning her funeral.

\section{GORGINA LOVELL Vancouver, BC, Canada; ginny@you-are-the-target.com}

\section{Germany: BAT's sick notes}

BAT Germany recently released its social report for 2003. Where tobacco is concerned, Germany is the sick man of western Europe. Rampant tobacco promotion saturates youth oriented media, especially student publications, and the government is infamous among its European Union partners for taking a fiercely pro-tobacco line at intergovernmental negotiations (see Tobacco Control 2002;11:90, 291-3). So it takes more than average industry duplicity for a German tobacco company to portray itself as socially responsible.

But even German health advocates, accustomed to industry excesses not seen for many years in other western European countries, were amazed to see the front cover of this entirely predictable example of the tobacco industry's "We've changed" public relations policy.

At first glance, and even on a second inspection, the cover of the latest glossy bundle of industry make believe, which differed significantly from that of BAT's first social report (June 2002), bore an unmistakeable resemblance to a German public health report on tobacco published in September 2002.

Many tobacco companies have parodied the design of health documents, often to try to devalue them, or even use them as crude marketing ploys (for example, BAT's "Think and Win" scheme in Uganda, taking off the international Quit and Win smoking cessation programme-see Tobacco 

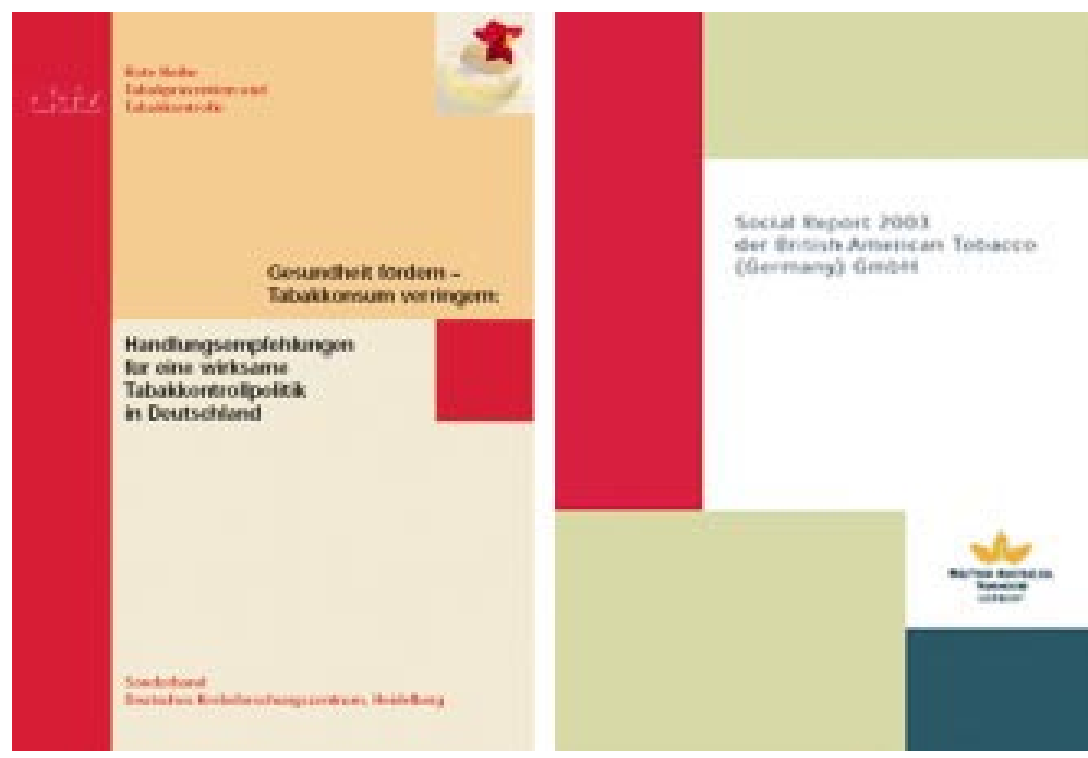

Spot the difference! The covers of the German public health report on tobacco (left panel) and BAT's own social report for 2003 (right panel).

Control 2000;9:271). Nowadays, as part of their attempts to reinvent themselves after exposure of their past dishonesty in the Minnesota documents and similar revelations, big tobacco companies are trying a different approach. They attempt to set up dialogues with health organisations and others that are trying to address the massive damage to health caused by tobacco, as if to suggest that they are somehow linked together as colleagues.

It is hard to escape the conclusion that BAT wanted to associate itself with public health policy, to be seen as an equal voice discussing policy to tackle Germany's largest preventable disease problem, or even just to create confusion to take the focus off the well publicised health report. That report, from the highly respected Deutsches Krebsforschungszentrum (the German cancer research centre DKFZ), contains a comprehensive summary of the current state of knowledge on tobacco control issues, and sets out recommendations for effective action to curb Germany's tobacco epidemic. The tobacco industry supports none of them; and its only pretence at action, the familiar cosmetic, ineffective youth campaigns, are probably making things worse.

ANNETTE BORNHÄUSER DKFZ, Heidelberg, Germany; a.bornhaeuser@dkfz.de

\section{Australia: smoke to be thin}

"Smoke to be Thin" screamed the women's T shirt that will become a test of Australia's tobacco advertising laws prohibiting the publication of tobacco advertisements.

Quit Victoria purchased one of the figure hugging women's $\mathrm{T}$ shirts in Melbourne; similar shirts were purchased in Perth, Western Australia. SUPRÉ, with 101 stores across Australia, describes itself as a hip brand for young women. SUPRÉ's website says its mission is to be at the forefront of global youth fashion: "SUPRÉ will definitely achieve this by focussing on: more fashion, better music, maximum excitement, total fun and much more sex appeal!!" However, the sale of the shirt may breach section 15 of Australia's Tobacco Advertising Prohibition Act. The Act defines a "tobacco advertisement" to mean "any writing ...that

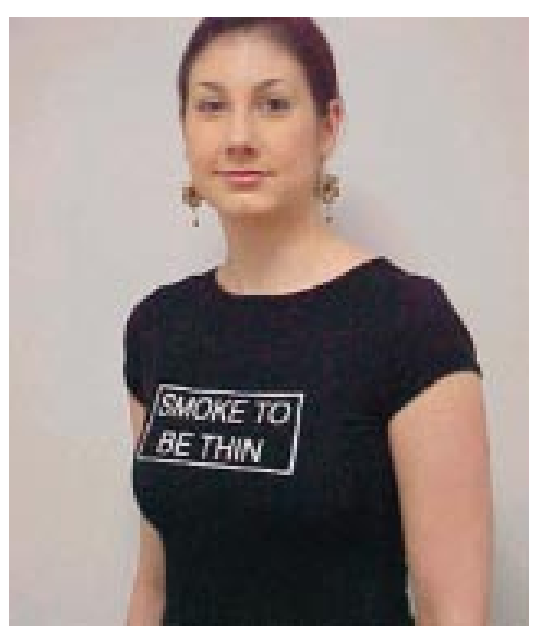

T shirts featuring this distinctly unhelpful message directed at young women went on sale in Australia, but were subsequently withdrawn. gives publicity to, or otherwise promotes or is intended to promote ...smoking."

The Australian fashion industry is laced with examples of making smoking a chic accessory. Leading fashion designer Wayne Cooper has been in the spotlight for antics such as sending models down the runway with provocative slogans on $\mathrm{T}$ shirts such as "Can I Smoke In Here?". The most insidious linkage of fashion and smoking has occurred through fashion events set up by Philip Morris under the guise of the "Wavesnet" brand. SUPRÉ defended its actions, saying it was a "tongue in cheek" exercise poking fun at girls who smoke to be thin.

"We are in the business of selling clothing and putting smart-alec slogans on clothing. I really don't understand the drama," said general manager Stephen Patrick. Despite this, the company withdrew the $\mathrm{T}$ shirt: "Clearly it was inappropriate and the shirt never went into full production," Mr Patrick said. Quit Victoria has referred the matter to the Australian government for action under the Tobacco Advertising Prohibition Act. The Act carries a maximum penalty of A\$12 000. Around 6000 women die in Australia each year from smoking related illness. The $\mathrm{T}$ shirt trivialises the leading cause of preventable death among Australian women. It seems almost beyond belief that a clothing chain that targets young women would actively promote such an irresponsible message.

TODD HARPER

Quit, Melbourne, Australia; Todd.Harper@cancervic.org.au

\section{Sri Lanka: BAT's hack trick}

Despite persistent activity by energetic and dedicated groups and individuals in Sri Lanka, there is still little sign of the government really embracing tobacco control; and there are still frequent reminders of which side seems to be winning the tobacco war. One reason may be that in official circles, and among the business community, the tobacco industry is still not seen as the pariah it is, allowing it access to activities that only serve to prolong its ability to suppress the widespread dissemination of the health message.

The Editors Guild of Sri Lanka recently honoured five senior journalists with gold medals for long and distinguished service, at its annual "Journalism Awards for Excellence" 


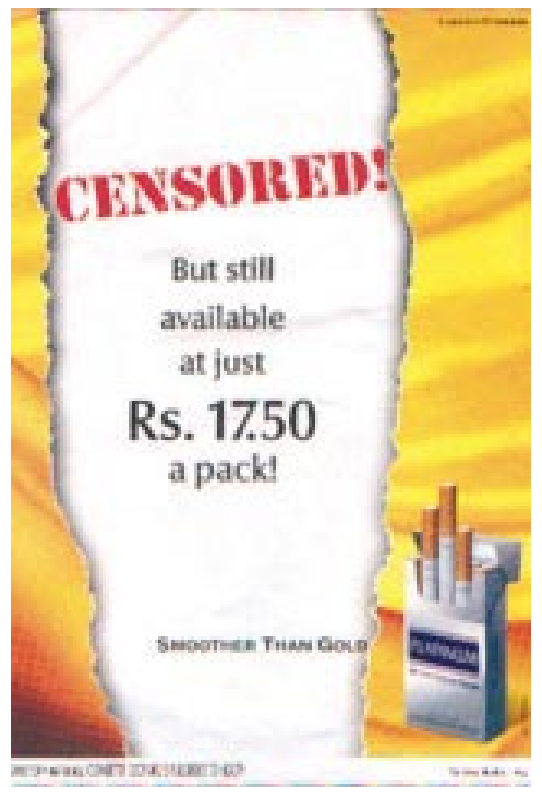

No sooner had the Indian parliament declared a ban on tobacco advertising and promotion than Godfrey Philips, Indian subsidiary of Philip Morris, placed this ad on billboards all over Mumbai (formerly Bombay), promoting its Platinum cigarettes. In addition, they got the popular local newspaper Mid Day to distribute leaflets carrying the same ad, with more printed on many pages. The leaflet also announced a contest, for which entrants had to buy the cigarettes. Ironically the leaflet, titled "Understanding Women", explored the emerging roles of the new Indian woman. As with many countries in the region, cigarette smoking rates are low among women, presenting a tempting potential new market for western tobacco companies.

ceremony held at a prestigious hotel in Mount Lavinia. One of the co-sponsors was Ceylon Tobacco Company (CTC), BAT's local subsidiary. Others, who still do not seem to fear their brand images becoming tainted with tobacco, included a national airline, banks, the national lotteries board, the board of control for cricket, and several newspaper groups. In all the feel good publicity, it is hardly surprising to find a lack of reporting on the massive health and social costs imposed by the products of one of the sponsors; and journalists tempted to bite the hand that feeds the scheme are risking their copy being spiked, at the very least, or possibly more serious professional consequences. Last year, The Island newspaper printed comments from a health advocate criticising the awards scheme and pointing out how it prevented journalists from writing freely about tobacco. But this small success was short lived: two days later, the paper did a $U$ turn, running a sharp attack on the health worker's comments.
BAT uses the same trick in other countries. For several years, its sponsorship of a sports journalism award in Uganda seemed to do the trick, with few journalists willing to mention how utterly incompatible cigarettes were with sporting achievement. But eventually, bad publicity led the Uganda sports press association to give them the push (see Tobacco Control 2000;9:269-70). Sri Lankan colleagues can take heart that despite the seemingly impenetrable alliance between tobacco and the hacks, it can be done.

\section{USA: when Irish eyes are smarting}

Irish pubs are best known for their superb Guinness, outstanding music, and pervasive smoking. But, if Irish Minister of Health Michael Martin has his way, smoking will be gone by January 2004 from all Irish workplaces, including restaurants and pubs.

When he announced the legislation last spring, it made headlines throughout America and politicians from Maine to Florida declared, "If Ireland can do it, so can we". As a hidden benefit of the new law, other European nations may emulate the Celtic antismoking tiger. But it's not a done deal. Opposition is strong from pub owners who cite the supposed economic harm that the recent New York City smoking ban has had on its Irish bars.

Over the past few years, I have visited Ireland often, both north and south, exporting elements of the Massachusetts tobacco control successes to my ancestors' turf. Tom Power, the head of Ireland's office of tobacco control, understands that the basis of success is changing social norms through clean air policies. He is as politically savvy as any Irish American politician and used his skills to pass the ban. At a recent meeting in the Irish city of Dundalk, Tom asked me to find out if the claims about New York were true.

In June, a meeting in New York City on international tobacco education media campaigns provided that opportunity. It was held near the United Nations on 44th Street and 2nd Avenue. Walking around the hotel you'd think you were in Dublin. On every street corner there was an Irish pub, and on 50th Street and 2nd Avenue there were three. What a research opportunity! After dinner we put together a team of four expert researchers to study how the New York smoking ban affected the Irish bars. We also decided to study the brew.
I was joined by Simon Chapman, Editor of Tobacco Control, whose father had Irish blood, Scott Leischow of the National Cancer Institute, whose mother is a Rooney, a descendent from Cork, and Danny McGoldrick of Tobacco Free Kids, who has relatives from Donegal and holds dual US/Irish citizenship. To avoid biased responses, Simon posed as an Australian barworker from Sydney, a city considering a similar ban. We surveyed the Irish owners, workers or patrons of four public houses, querying them on the ban's effect on business, work environment, and rowdiness.

Of the four visited, none had significant compliance issues except one patron lighting up in the last establishment visited. He took it outside after a few silent stares. There was no significant smoking outside, and certainly no sidewalk disturbances, although the number of smokers congregating outside appeared to increase within the hour as evidenced by our return trip past one of the places visited earlier. None reported any fights or the like, typically saying "This is Manhattan". Some suggested that bars in the other boroughs probably were not complying.

Three of the four establishments stated that business was off (typically $20-30 \%$ ) since the ban, but two of those three were quite good natured about the situation, saying essentially that "it is what it is; you just deal with

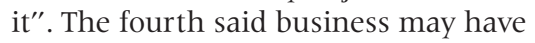
fallen off a bit immediately following the ban, but that he sensed it was already coming back. When asked about the potential for the ban in his homeland (Ireland), he replied that "it's going to happen everywhere" so we might as well get used to it.

None of the bars was packed, but nor were they by any means empty, especially for a quiet Wednesday night, and our sample was taken relatively early in the evening (roughly 9-11 $\mathrm{pm})$. The crowds appeared to grow as the night wore on. In at least one of the establishments, the four of us couldn't get a spot at the bar, but there were tables available. Their responses seemed scripted, and I thought back to comments I heard in Dublin that the pub owners of New York and Dublin were working together to oppose the Irish ban. A 2002 California study found meals and alcohol tax payments rose after its bars went smoke-free in 1998 and that by 2002, 75\% of bar owners and employees said they preferred to work in a smoke-free environment, compared to $47 \%$ in 1998 . A 
recent Irish survey found nearly 70\% of bar patrons supported the ban, including $40 \%$ of smokers. Of the $30 \%$ who oppose the ban, half were nonsmokers. It also found that $13 \%$ of people said they would visit bars more often for a drink once the ban was in place and $12 \%$ said they would visit less often. More interestingly, $20 \%$ said they would visit smoke-free bars more often for a meal compared to $7 \%$ who said they would visit less often. The place in which the barkeeper said business was coming back poured the best Guinness. Perhaps that's the key explanatory variable.

One bartender complained about everything from Mayor Bloomberg to anti-smoking zealots. The words he used to describe the Mayor would have shocked any Irish nun. I never met such a complainer in Ireland and concluded that he was really a New Yorker with a brogue. We found workers in all the pubs enjoying the smoke-free environment, no smelly clothes, and less risk of disease.

We concluded our research around $11 \mathrm{pm}$ with a toast to Mayor Bloomberg and the Irish health minister, Michael Martin. To our Irish cousins we can report that the city ban is working well. Stick with it and keep making the excellent brew. After all, "Guinness is good for you", as the advertising slogan used to say, but "Smoke-free Guinness is even better". As is the case with any such investigation, a great deal more research is by all means called for. We can't wait to do a follow up study in smoke-free Dublin next year. Slainte!
GREG CONNOLLY Boston, Massachusetts, USA; gregconn@ix.netcom.com

DANNY MCGOLDRICK New York, NY, USA; dmcgoldrick@TobaccoFreeKids.org

\section{UK: gutter press}

Now that new, stronger health warnings are beginning to appear on British cigarette packs, a new form of health education has been appearing up and down the country. Thanks to the careless habits of many British smokers, who discard massive amounts of cigarette litter on pavements and streets every day, the eye of even the least curious pedestrian is frequently caught by stark messages blaring out from the gutter.

One hardened smoker, a journalist on the tabloid Daily Mirror, admitted he was so alarmed by the stark messages that he resolved to quit. "I was queuing for a packet of 20, minding my own business, when I saw the words screaming at me from behind the counter: 'Smoking clogs the arteries and causes heart attacks and strokes' and 'Smoking can cause a slow and painful death.' And these aren't just anybody's arteries, heart, skin or lungs-the warnings seem to be aimed at me in particular."

The new series of warnings, one on the front and a different one on the back of every pack, have triggered a large increase in calls to the National Health Service's smoking telephone help line. More than 10000 people said they were driven to call by the

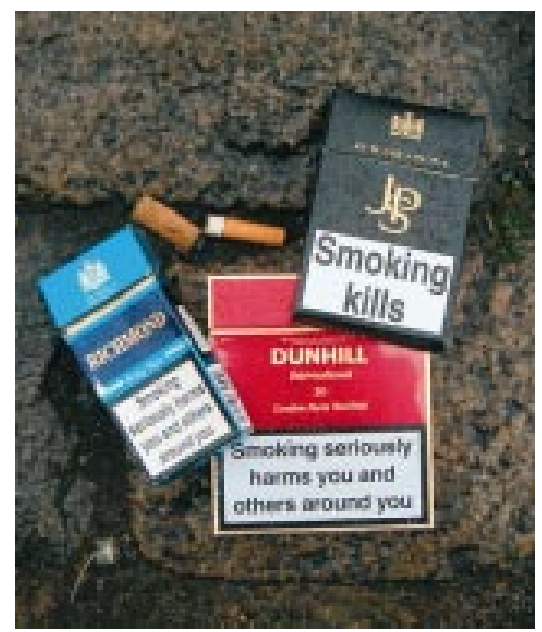

Bolder warnings on cigarette packs sold in the UK appear to be having the desired effect, with calls to smoking help lines greatly increasing

new labels during the first four months of 2003, an increase of $12 \%$ in call levels. The new warnings, introduced in January following a European Union directive, cover $30 \%$ of the front of cigarette packets and $40 \%$ of the back. A thick, black border adds a further $10 \%$ to the warning area. All cigarette packets sold in the UK must carry the warnings by September.

\section{Middle East: religion against tobacco}

Tobacco use is a social problem and controlling it requires real change in social beliefs and norms. One thing that has worked successfully in this regard throughout the centuries in countries
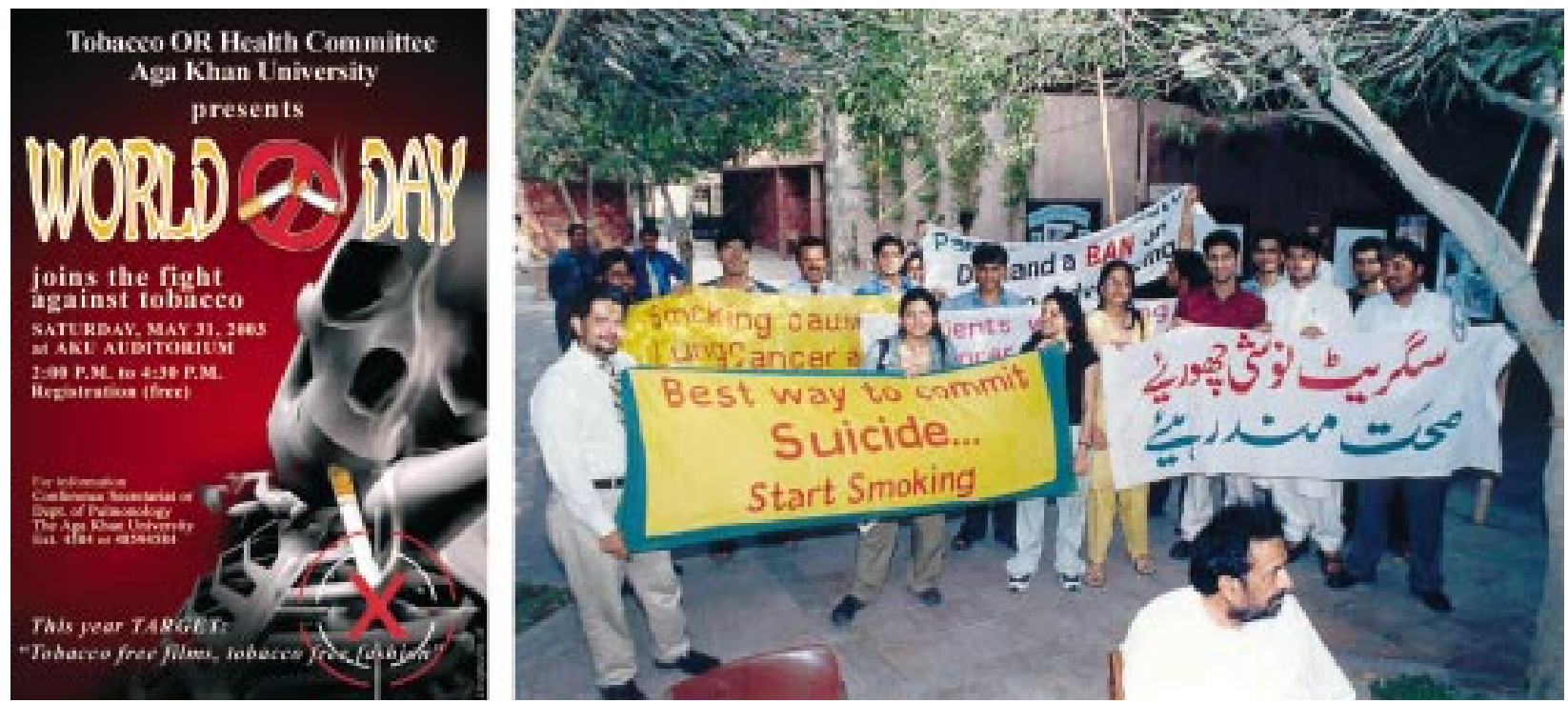

In Pakistan, health advocates designed posters to promote activities for World No Tobacco Day in May, including this one (left panel). Others were printed in national newspapers, sponsored by GlaxoSmithKline. Equally eyecatching were these banners with robust messages about tobacco, used in a rally in Karachi (right panel). 
of the Eastern Mediterranean region is religion. Thus, whenever possible, a religious message should be activated at all different levels.

Under a plan of action developed in the World Health Organization's Eastern Mediterranean Regional Office (EMRO), the fatwa (religious edict) on smoking, issued by the Grand Mufti of Egypt, was summarised and the summary approved by the Grand Mufti himself as well as the national authority concerned. Eighty thousand posters of the summarised ruling were prepared and distributed all over Egypt within five days during the month of Ramadan.

Of these 80000 posters, 53000 were distributed to mosques. The poster was also placed in main squares and streets, and Egypt's Minister of Health and Population decided to have it displayed in all public hospitals.

EMRO staff also met the Pope of the Coptic Church, after which he requested a bishop to write on the Christian view on smoking (http:// www.emro.who.int/tfi/EMROleadschristianview.htm). This was translated into English and posted on the TFI/EMRO website in connection with the 2001 WNTD.

Moreover, Saudi Arabia is one of EMRO's key member states that has exerted tremendous efforts, particularly during the last pilgrimage season (2003), in activating and promoting the religious message in the two holy cities of Mecca and Medina. In February 2003, billboards carrying antismoking messages were posted all around Mecca. Posters, brochures, pamphlets, and stickers were also handed out to three million pilgrims, in six different languages.

Similar activities were also adopted in Medina; 500000 brochures and pamphlets were distributed as well as
5000 posters and 5000 tapes. Moreover, retailers are required to post antismoking messages and health warnings on the front windows of their shops; licences are neither being given nor renewed to tobacco agents, whose operations have now been moved to the outskirts of Medina; 20 restaurants, cafés, and similar establishments were closed during the morning hours, to prohibit them from selling shisha (tobacco mixed with molasses and fruit flavours) to students; antismoking committees were formed in various localities to spread the tobacco control message; and due to cultural sensitivities, a committee of women was also formed to carry the message of tobacco control to women.

These awareness campaigns in Medina led to more than 3000 men and 1600 women calling in, requesting information on smoking related issues. In addition, 200 retailers have stopped selling tobacco products. In Mecca and Medina, both smoking and the sale of cigarettes have been prohibited within a certain radius of the holy mosques as well as near schools. In addition, no form of tobacco advertising is now permitted around these holy zones.

FATIMAH EL AWA EMRO-WHO, Cairo, Egypt; AlAwaF@emro.who.int

\section{Nigeria: experience it, die from it}

Last November, BAT launched a promotional campaign called "Experience It" in Nigeria, featuring five blockbuster Hollywood films. All five movies screened or advertised-Ocean's Eleven, Matrix, ShowTime, Romeo Must Die, and Collateral Damage-are Warner Bros productions. The promotional campaign was national, reach-

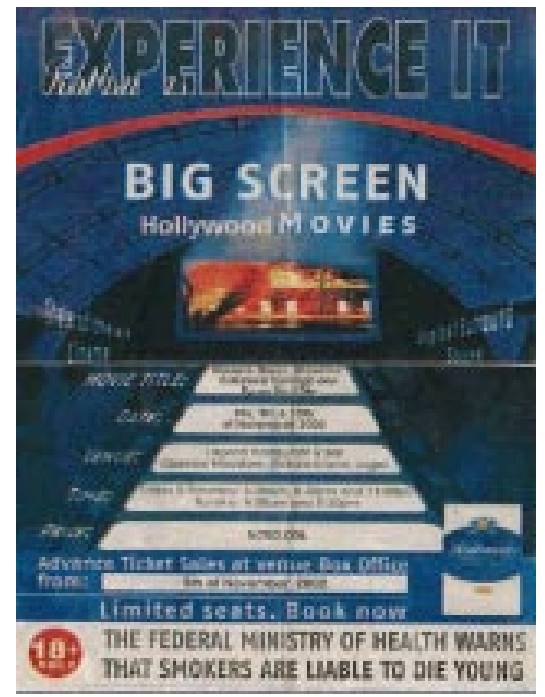

BAT's promotional campaign, "Experience It", featuring five Hollywood movies. At the events, young people were given free cigarettes, and even given help to light them.

ing six geopolitical regions. At "Experience It" events, young people were given free cigarettes and "starters", as they tend to be known among tobacco industry people, were helped to light them. The venue was a 500 seat dome with wide screen. BAT defended the campaign, saying that it was to "promote cinema culture", but health advocates say the campaign was really used to launch new packaging for Rothmans cigarettes. Nigeria has no tobacco control regulation and the government actively supports BAT activities.

ADEOLA AKINREMI SEUN AKIOYE

Journalists Advocacy for Safe Environment \& Tobacco Eradication, Lagos, Nigeria; adeolaakinremi@yahoo.com genius@journalist.com 